\title{
Dynamic variability of the heading-flowering stages of single rice in China based on field observations and NDVI estimations
}

\author{
Zhao Zhang • Xiao Song • Yi Chen • Pin Wang • \\ Xing Wei $\cdot$ Fulu Tao
}

Received: 8 May 2014 / Revised: 9 July 2014 / Accepted: 12 July 2014 / Published online: 23 July 2014

(C) ISB 2014

\begin{abstract}
Although many studies have indicated the consistent impact of warming on the natural ecosystem (e.g., an early flowering and prolonged growing period), our knowledge of the impacts on agricultural systems is still poorly understood. In this study, spatiotemporal variability of the heading-flowering stages of single rice was detected and compared at three different scales using field-based methods (FBMs) and satellite-based methods (SBMs). The headingflowering stages from 2000 to 2009 with a spatial resolution of $1 \mathrm{~km}$ were extracted from the SPOT/VGT NDVI time series data using the Savizky-Golay filtering method in the areas in China dominated by single rice of Northeast China (NE), the middle-lower Yangtze River Valley (YZ), the Sichuan Basin (SC), and the Yunnan-Guizhou Plateau (YG). We found that approximately 52.6 and $76.3 \%$ of the estimated heading-flowering stages by a SBM were within \pm 5 and \pm 10 days estimation error (a root mean square error (RMSE) of 8.76 days) when compared with those determined by a FBM. Both the FBM data and the SBM data had indicated a similar spatial pattern, with the earliest annual average heading-flowering stages in SC, followed by $\mathrm{YG}, \mathrm{NE}$, and $\mathrm{YZ}$, which were inconsistent with the patterns reported in natural ecosystems. Moreover, diverse temporal trends were also detected in the four regions due to different climate conditions
\end{abstract}

Electronic supplementary material The online version of this article (doi:10.1007/s00484-014-0877-6) contains supplementary material, which is available to authorized users.

Z. Zhang $(\bowtie) \cdot$ X. Song $\cdot$ Y. Chen $\cdot$ P. Wang $\cdot$ X. Wei

State Key Laboratory of Earth Surface Processes and Resources Ecology/Key Laboratory of Environmental Change and Natural Disaster, MOE/Academy of Disaster Reduction and Emergency Management, Beijing Normal University, Beijing 100875, China e-mail: zhangzhao@bnu.edu.cn

F. Tao

Institute of Geographical Sciences and Natural Resources Research, Chinese Academy of Sciences, Beijing 100101, China and agronomic factors such as cultivar shifts. Nevertheless, there were no significant differences $(p>0.05)$ between the FBM and the SBM in both the regional average value of the phenological stages and the trends, implying the consistency and rationality of the SBM at three scales.

Keywords Spatiotemporal $\cdot$ Heading-flowering · Phenology $\cdot$ NDVI $\cdot$ Single rice

\section{Introduction}

Phenology is the chronology of the periodic phases of the development and reproduction of living species. Climate impacts on the phenological changes of vegetation have become increasingly concerned in recent decades under ongoing climate change and variability (Doi et al. 2010; Ibanez et al. 2010; Wang et al. 2011). In particular, the warming trend of the climate, which is unequivocally confirmed by a scientific consensus (IPCC 2013), will undoubtedly impose significant influences on vegetation growth and phenology. Vegetation phenology could vary due to short-term climate fluctuations and shifts as a result of the long-term trend of climate change. Thus, monitoring the key phenological stages over wide areas is of fundamental importance for agricultural management, irrigation, models calibration and validation, identifying the spatial distribution of vegetation types, and analyzing the plant response to climate change (Dingkuhn and Le Gal 1996; Tubiello et al. 2007; Thornton et al. 2009; Sacks and Kucharik 2011; Foerster et al. 2012; Zhang and Tao 2013).

Phenological changes had been observed in different ecological systems throughout the world, including America (Bradley et al. 1999), China (Chen et al. 2005), Germany (Menzel et al. 2001; Chmielewski et al. 2004; Estrella et al. 2007; Siebert and Ewert 2012), UK (Sparks et al. 2000), Southern Spain (García-Mozo et al. 2010), Lithuania, and 
Latvia (Romanovskaja et al. 2009). The observed ecosystems extended from natural vegetation (e.g., forest and grass) (Badeck et al. 2004; Morin et al. 2010) to crop systems (e.g., soybean, wheat, and rice) (Setiyono et al. 2007; Tao et al. 2012; Zhang et al. 2013). Relatively many phenological studies on the natural vegetation have been conducted and consistent results have been concluded, such as advanced flowering, prolonged growth period, and delayed defoliation (Sparks and Carey 1995; Fitter and Fitter 2002; Menzel et al. 2006; Piao et al. 2006; Karlsen et al. 2009). However, the results in crop systems are still under critical debate due to the frequent influence of human activity. For example, Tao et al. (2012) found that nearly $40 \%$ of more than 100 national agrometeorological experiment stations across China indicated a significantly advanced trend for heading-flowering stage and maturity stage for wheat. Meanwhile, the lengths of the growing period and vegetative growing period exhibited a significantly decreasing trend at approximately $30 \%$ of the investigated stations, in contrast to a prolonged reproductive period at approximately $60 \%$ of the stations. Moreover, Tao et al. (2013) further proved the relationship between rice phenological change and warming varied in different rice cultivated systems, cultivars, and rice growing periods. In the study of the spatiotemporal changes in maize phenology, temperatures and their correlations in Northeast China (NE) between 1990 and 2012, Li et al. (2014) found significantly advanced seedling/heading dates, delayed maturity dates, and increased growing periods at more investigated stations, which indicated the substantial influence of agronomic factors on the shift in maize phenology. In any case, acquiring the phenological data over wide areas is essential and challenging for the current scientific studies.

Generally, there are two methods, FBMs and SBMs, to obtain the crop phenological information. Traditional FBMs are time consuming and costly, impractical to extend to large areas (Sakamoto et al. 2010). By contrast, SBMs with a large spatial coverage and periodic sampling has great potential for monitoring vegetation growth at multiple scales. However, many previous studies on crop systems using SBMs has focused on only very limited areas (Wang et al. 2012), and only a few studies are conducted at national and global scales due to the complexity of dealing with multiple crops within a growing season (Sehgal et al. 2011; Wu et al. 2010). Here, we applied both a FBM and a SBM to diagnose the dynamics of the key phenological stage (heading-flowering) of single rice in China since heading-flowering stage is recognized as a critical period in the reproductive phase, significantly influencing the final yield (Moldenhauer and Slaton 2001). The FBM was based on the newly observed data at 58 agrometeorological stations (AMSs) across the major single rice cultivation regions of China, spanning the years from 2000 to 2009, and the SBM on the NDVI time series data in East Asia using the Savizky-Golay (SG) filter method. We aimed to understand in the latest decade: (1) the spatial pattern of the heading-flowering stage of single rice at three different spatial scales (AMS, grids adjacent to the station (GAS), and grids in the entire region (GER)), (2) the extent of change, if any, of the heading-flowering stages at three spatial scales, and (3) the ability of SBM to capture the heading-flowering stage of single rice at the national scale.

\section{Data and method}

Study area and data sources

The single rice cultivation regions in China were divided into four regions: NE, the middle-lower Yangtze River Valley (YZ), Sichuan Basin (SC), and Yunnan-Guizhou Plateau (YG) (Mei et al. 1988; Papademetrieu 2000) (Fig. 1). There were a total of 58 different AMSs in the study area, including 15 stations in NE, 14 stations in YZ, 16 stations in SC, and 13 stations in YG. The observations from 2000 to 2009 at each AMS included detailed information, such as station number, station name, province name, latitude, longitude, year, and days of the year (DOY) for the heading-flowering stages that were the critical periods in the reproductive phase influencing the final rice yield.

In addition, SPOT VGT-S10 NDVI products (10-day composites of 1-km resolution) in East Asia from 2000 to 2009 were used to represent the spectral reflectance characteristics of the single rice. To diminish the atmospheric noise and negatively biased noise caused by clouds, the data products were developed by the maximum value compositing (MVC) method to select the best ground reflectance value in the 10day period (Holben 1986), which resulted in 36 composites in 1 year. In addition, the status map containing the data flag, cloud, and land mask information was also adopted to determine the quality of the NDVI value.

To determine the single rice cultivation region, data for land use in a 1-km grid of China in 2005 was obtained from the Data Sharing Network of Earth System Science (http:// www.geodata.cn/Portal/).

\section{Method}

The trajectories of the NDVI time series curve were linked closely with the crop phenological processes (McCloy and Lucht 2004), and many previous studies had successfully identified phenological phases of natural vegetation according to the characteristics of the NDVI seasonal variation (Kross et al. 2011; Cong et al. 2012; Jeganathan et al. 2014). Here, we focused on the heading-flowering stages of single rice. First, the original SPOT/VGT NDVI datasets in East Asia were clipped to the official boundary of China according to the China administrative map. Second, for the type of paddy field, 


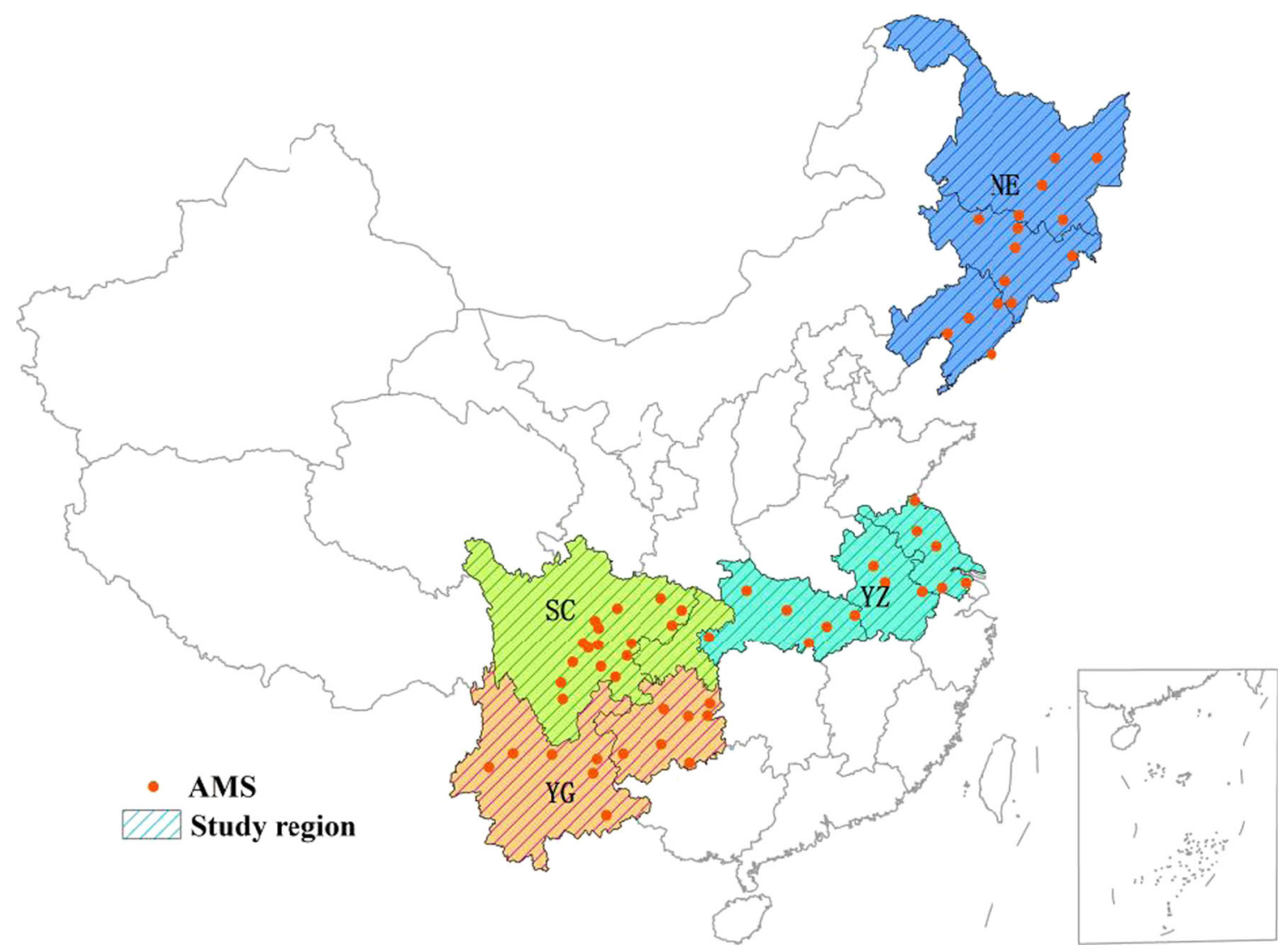

Fig. 1 Single rice cultivation region in China and the locations of agro-meteorological stations (AMSS) used for validation in this study in Northeast China $(N E)$, the middle and lower reaches of Yangtze river (YZ), Sichuan Basin $(S C)$, and Yunnan-Guizhou Plateau $(Y G)$

only the land use grid percentage value larger than $50 \%$ was selected to be regarded as the typical rice-growing area. Third, combined with the typical rice-growing area, the NDVI timeseries dataset was obtained for the following analysis. Last, the SG fitting function was used for data filtering and removing noise to reconstruct smooth NDVI time-series data, extracting the key phenological stage data for each of the growing season from 2000 to 2009. To decrease the influence of the low quality pixel and achieve better fitting results, the quality data (including the data flag, cloud, and land mask information) was used for assigning weights before applying the fitting model function. Here, the high-quality weight was set to 1 , the low-quality weight was set to 0.2 , and the poorquality weight was set to 0.1 . Furthermore, combined with the observed data at AMSs using the FBM, subsequent analysis of the spatial pattern and temporal trends of the key phenology stage was conducted at different scales (Fig. 2).

\section{Savitzky-Golay filtering method}

Generally, there are several filtering methods, such as SG, Asymmetric Gaussian and Double Logistic functions, available to explore and extract a number of seasonality parameters (Jonsson and Eklundh 2002,
2004). SG filtering was used in this study for smoothing and suppressing the disturbances to obtain a reconstruction of the NDVI datasets according to Eq. (1). This method was developed to make data approach the upper NDVI envelope and to reflect the changes in NDVI patterns via an iteration process. It has been demonstrated to be very simple in theory and easy to implement to obtain high-quality NDVI time-series (Savitzky and Golay 1964; Chen et al. 2004).

$\mathrm{NDVI}_{i}^{*}=\frac{\sum_{j=-n}^{j=n} C_{j} \mathrm{NDVI}_{i+j}}{N}$

where $\mathrm{NDVI}_{i}$ is the original data value, $\mathrm{NDVI}_{i}{ }^{*}$ is the fitting result, $C_{j}$ is the coefficient for the $i$ th NDVI value, $j$ is the running index of the original ordinate data table, and $N$ is the number of convoluting integers and equals to the smoothing window size $(2 n+1)$. The weight coefficients $C_{i}$ perform a polynomial least-squares fit within the filter window, which is determined by two parameters: $n$ and $d$. $n$ is mentioned above as the half-width of the smoothing window, and $d$ specifies the degree of the fitting polynomial, with a typically range from 2 to 4 . 
Fig. 2 Flowchart of the principal steps taken in the article

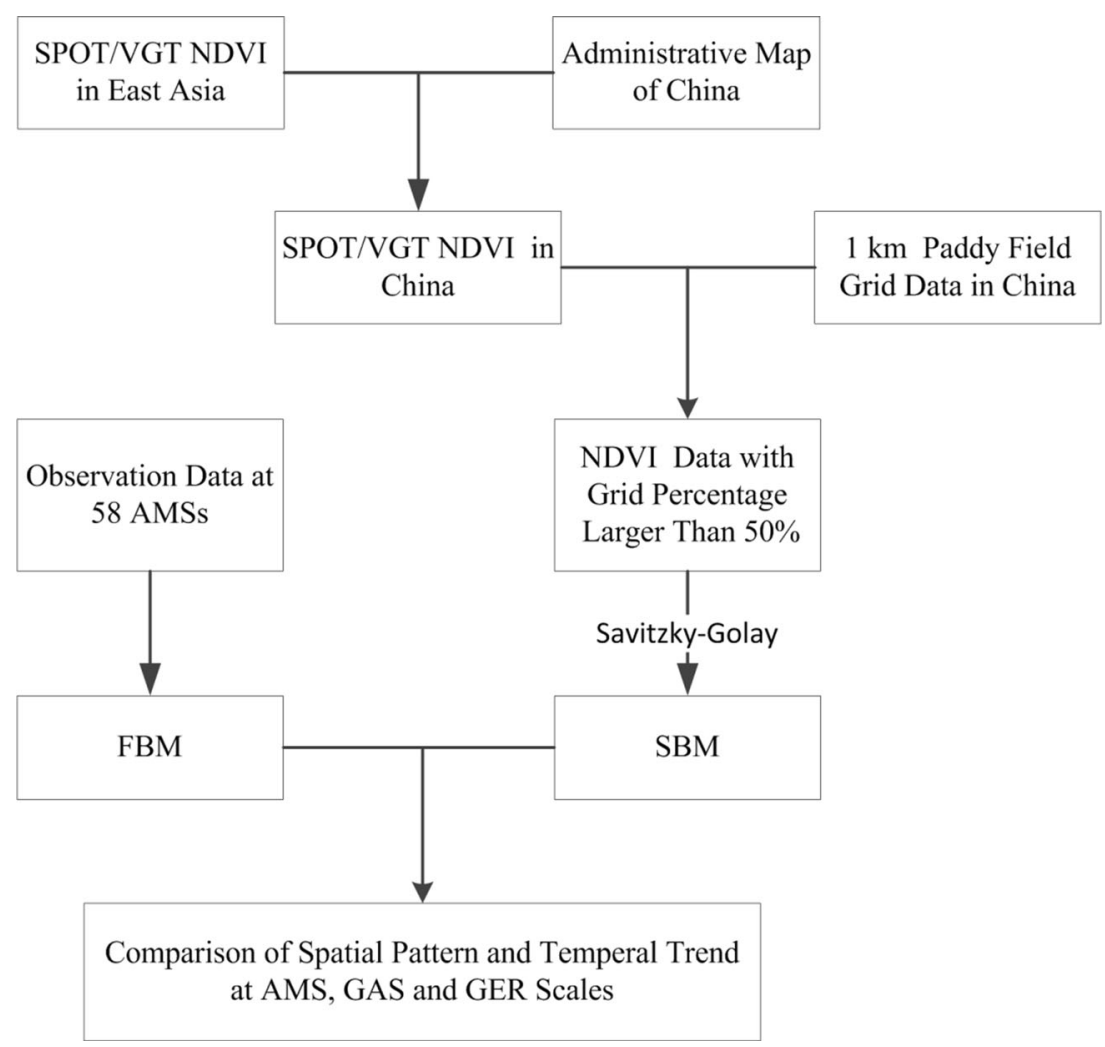

\section{Extraction of the heading-flowering stages}

The heading-flowering stages were identified as the time of the annual maximum on the fitted NDVI curve (Sun et al. 2009; Huang et al. 2013). Correspondingly, only one typical peak for single rice would be shown for most of grids during 1 year's running in NE (Fig. S1a). However, in a diversified cropping system, there existed more than one maximum of NDVI value in 1 year due to the crop rotation, such as wheat with rice and rice with other crops in the southern regions (YZ, $\mathrm{SC}$, and YG) (Fig. S1b). To avoid the extraction of such multiple peaks, a restricted time window (July to September) of the key phenological stage of the single rice must be used to exclude the disturbance of other rotation crops. Here, only the peak value within the time appropriate window was identified as the potential single rice. The 3-month limitations would not exclude the heading-flowering stage (Sun and Huang 2011).

\section{Definition of the three spatial scales}

The AMS scale was based on the 58 actual AMSs across the main single rice planting areas. Grid adjacent to a station (GAS) was the second scale, which was defined as the buffer with a $5-\mathrm{km}$ radius around an AMS. The average value of all pixels in the buffer was selected as the typical headingflowering stage at the GAS scale. For the third scale, the average value of all of the GER was used.

\section{Kernel density estimation and one-way ANOVA method}

Kernel density estimation is a nonparametric density estimation used to model the probabilistic or stochastic structure of a data set (Sheather 2004). It was used to estimate the distribution of heading-flowering stages in the four study regions and defined as Eq. (2).

$f^{\wedge}{ }_{h}(x)=\frac{1}{n h} \sum_{i=1}^{n} K\left(\frac{x-X_{i}}{h}\right)$

$K(u)=\frac{1}{\sqrt{2 \pi}} \exp \left(-\frac{1}{2} u^{2}\right)$

where $f^{\wedge} h(x)$ is the estimated density function of random variables $x . n$ is the number of sample $X_{i}$, and $h$ is bandwidth which controls the degree of smoothing applied to the sample data. $K(u)$ is the Gaussian kernel function defined as Eq. (3).

In statistics, one-way analysis of variance (ANOVA) is a method to compare means of two or more samples using the $\mathrm{F}$ distribution (Howell 2002). Here, the method was used to analyze the difference of the spatiotemporal patterns of the heading-flowering stages at three spatial scales. 


\section{Results}

Validation of the phenological data between the AMS and GAS scales

One-to-one comparison between the observed and the estimated heading-flowering stages at the AMS and GAS scales is shown in Fig. 3, which depicts the performance of SG filtering method for detecting the key phenological stage. Generally, for all of the AMSs across the entire study region, the amounts of points scattered closely around the 1:1 line indicated the accuracy of the SBM compared with the FBM. In addition, note that the estimated time derived from the fitting curve had a minimum allowed error of \pm 10 days because the NDVI data used here was a 10-day composite product without an exact time of the scene acquisition (Bradley et al. 2007). As in Fig. S2, the percentage of the number of cases in which the estimation error was within \pm 5 and \pm 10 days for the entire single rice cultivation region was 52.62 and $76.31 \%$, respectively. Only $23.69 \%$ of the cases exceeded \pm 10 days of estimation error, which were acceptable considering the large scale and complex local environment. In addition, the root mean square error (RMSE) of the estimated key phenological stages estimated by the SBM at the GAS scales was 8.76 days from 2000 to 2009 .

However, the SG filtering method exhibited different performance abilities for detecting heading-flowering stages in different single rice cultivation regions. The estimation at the GAS scales in NE had the best results with 70.14 and $95.83 \%$ cases within \pm 5 and \pm 10 days estimation errors, respectively. Meanwhile, cases with estimation error exceeding \pm 10 days accounted for only $4.17 \%$. By contrast, with regard to the cases in $\mathrm{YZ}, \mathrm{SC}$, and $\mathrm{YG}$, the percentage with an estimation error within \pm 5 days reached $44.55,41.18$, and $48 \%$, respectively, while $69.31,61.34$, and $72 \%$ of the cases in YZ, SC, and $Y G$, respectively, was within \pm 10 days. YG had a better estimation performance than the other two regions. In addition, the RMSE of estimated key phenological stages at the GAS scale in NE, YZ, SC, and YG were 5.12, 9.44, 10.16, and 10.73 days, respectively, which also demonstrated the different estimation performances in each region.

Spatial distribution patterns of the annual average headingflowering stages of single rice at the AMS, GAS and GER scales

Generally, the heading-flowering stages of single rice should be in the period between July and September according to the traditional cropping calendar. As depicted in Fig. 4, a distinctly different spatial pattern of the annual average headingflowering stages ranging from 195 to 255 days was found at both the AMS and GER scales. At the AMS scale, most of the value in $\mathrm{YZ}$ was larger than those of the other three cultivation regions, indicating a later heading-flowering stage. In YZ, six stations located in the eastern part exhibited a larger value (231-255) than those of the other eight stations in the Midwest (221-230). By contrast, the value in SC was the smallest among the four regions, with an observed early headingflowering stage, while the range of values in $\mathrm{NE}$ and $\mathrm{YG}$ was between the above two regions. In SC, the southeastern part including nine stations had earlier stages (195-210) than the seven stations in the northwest (211-230). In NE, three stations out of the 15 AMSs located in the east had late stages (221-231). Similarly, most stations in YG had stages before
Fig. 3 The scatter plots of the observed and estimated headingflowering stages of single rice at AMS and GAS scales in China during 2000-2009

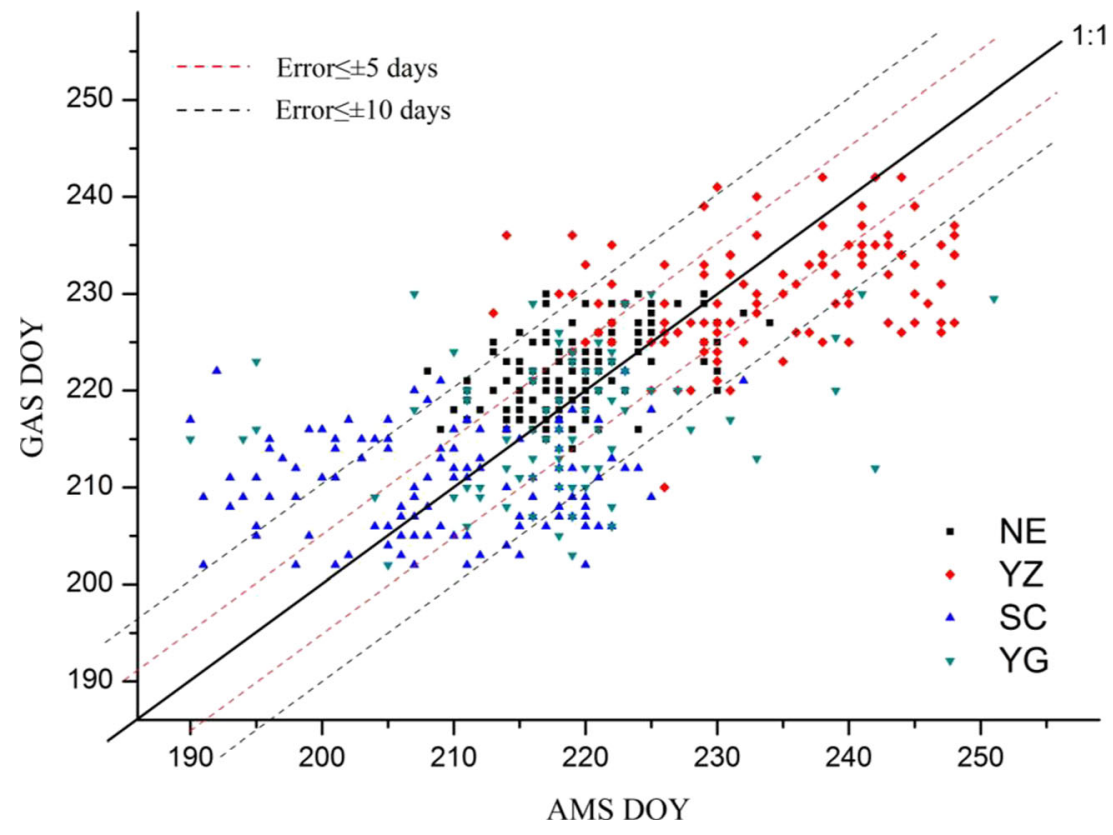




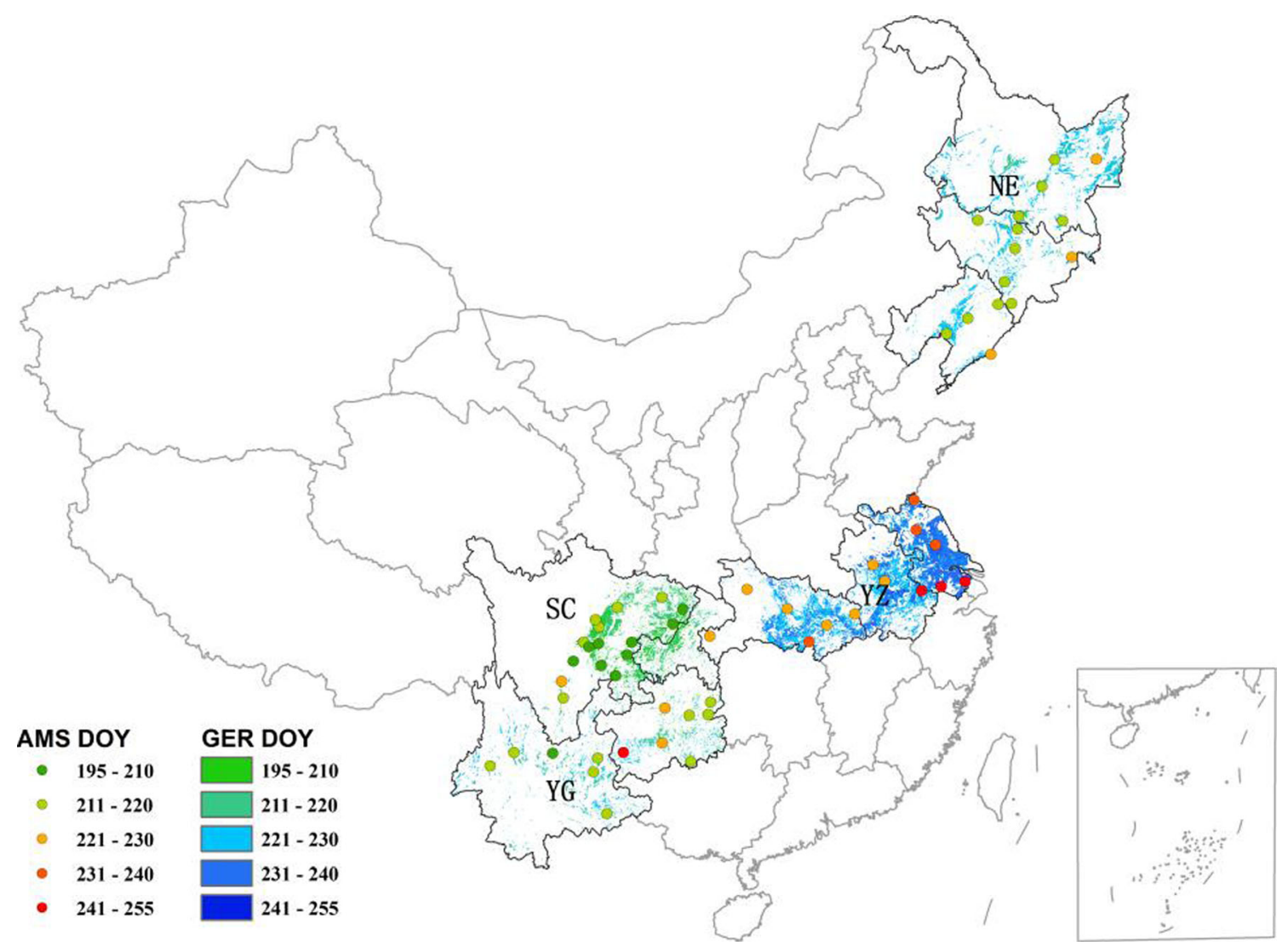

Fig. 4 The spatial distribution patterns of the annual average heading-flowering stages of single rice at AMS and GER scales in China during 20002009

220 days, with only three stations in the middle part being later than that. At the GER scale, a similar spatial distribution pattern was also displayed compared with the AMS scales. For all of the grids in NE, YZ, SC, and YG, the headingflowering stages had an average value of $221.8 \pm 2.2$ (spatial SD), 231.4 \pm 5.1 (SD), 211.1 \pm 3.1 (SD), and 219.5 \pm 5.0 (SD), respectively. Apparently, regions in the YZ and YG exhibited a larger spatial variability than the other two regions.

Furthermore, across each cultivation region, the annual average heading-flowering stages at three scales (AMS, GAS, and GER) were compared to demonstrate the rationality of using the SBM in monitoring the phenology at a large area. In Fig. 5, during 2000 to 2009, the median value (day) of the annual average phenological stages was 218.8, 221.3, and 221.8 in NE at the AMS, GAS, and GER scales, respectively. In YZ, the median value was 230.3, 229.4, and 231.0 at the AMS, GAS, and GER scales, respectively. Similarly, the median value was 208.2, 209.3, and 211.0 at the AMS, GAS, and GER scales, respectively, in SC, while it was 218.5, 217.2, and 219.4 at the AMS, GAS, and GER scales, respectively, in YG. For the regional average value (day), it was 219.0, 221.9, and 221.8 in NE, 232.9, 229.8, and 231.4 in YZ, 209.1, 210.6, and 211.1 in SC, and 218.2, 216.9, and 219.5 in YG at the AMS, GAS, and GER scales, respectively. Generally, the median and average value of the annual average phenological stages at three scales in the four regions were very close, indicating the rationality of SBM to some degree.

Kernel density estimation of the distribution of the headingflowering stages in the four regions

In fact, the rice heading-flowering stages were heterogeneous at both the spatial and inter annual time scales due to the different rice varieties and growing conditions. However, in a specific region with similar climate conditions, the headingflowering stages should follow a certain distribution that is limited within a time domain. Figure 6 shows the probability distribution curves derived in the four study regions using the kernel density estimation method according to the estimated annual average heading-flowering stages at the GER scale. The heading-flowering stages could be reported with a $95 \%$ confidence in the interval of 218.1 to 225.5 in NE, 222.9 to 240.5 in YZ, 206.0 to 216.2 in SC, and 211.4 to 228.3 in YG. The probability density curve derived by the kernel density estimation indicated the phenological distribution in the similar cultivation region, which had been shortened from the referring 3-month time window to approximately 20 to 30 days. In addition, a distinct temporal difference in different regions was found, which well reflected the different time 
Fig. 5 Box plot of annual average heading-flowering stages of single rice across NE, YZ, SC, and $\mathrm{YG}$ at AMS, GAS, and GER scales respectively, during 2000 2009

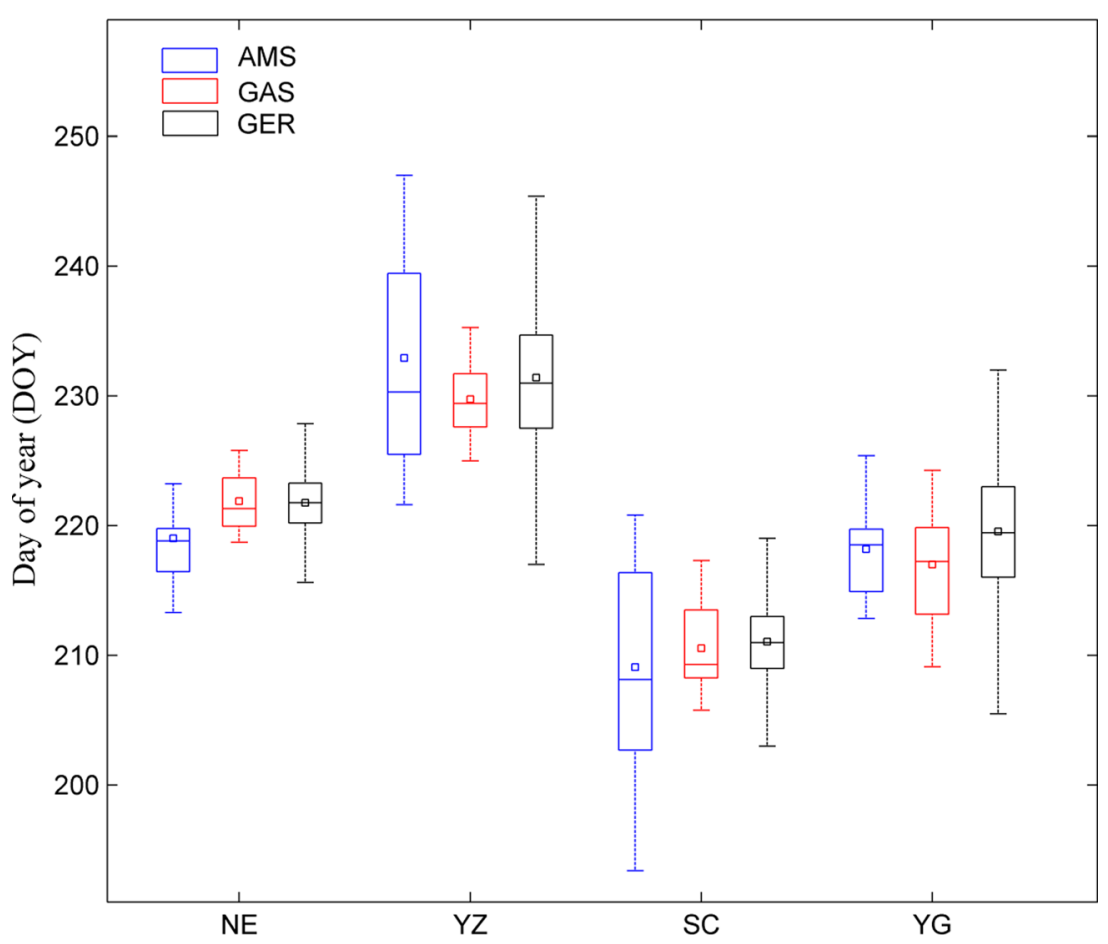

ranges of the heading-flowering stages. The cumulative probability curve was also depicted in Fig. 7.

Temporal trends in the heading-flowering stages of single rice at the AMS, GAS and GER scales

As shown in Fig. 8, the temporal trends exhibited large spatial differences in the entire country. The heading-flowering stages of single rice were generally delayed at 34 stations (58.6\%) of the investigated 58 stations during 2000-2009.
However, an obvious regional pattern was found for the four cultivation regions. At the AMS scale, the heading-flowering stages were delayed at 12 stations (80\%) in NE. In YZ, the heading-flowering stages advanced at nine stations $(64.3 \%)$, of which most were concentrated in the eastern part. In SC, five stations $(31.23 \%)$ in the middle part exhibited advanced phenological stages, while the remaining 11 stations indicated to delay over the 10 years. By contrast, the middle part of YG exhibited a delayed trend at six stations (46.2\%) of the13 investigated stations. Using the SBM, a similar spatial pattern
Fig. 6 The probability density curve of the annual average heading-flowering stages (day) at GER scales estimated by kernel density method in four regions, respectively

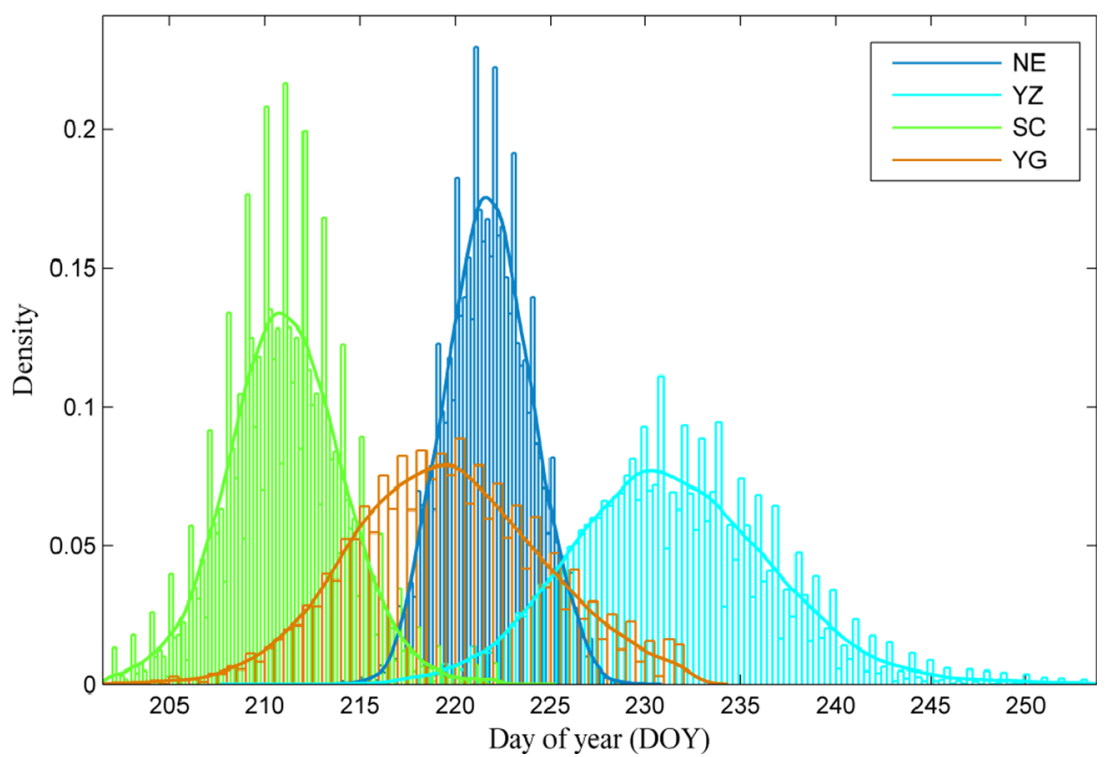


Fig. 7 The cumulative probability curve of the annual average heading-flowering stages (day) at GER scales estimated by kernel density method in four regions, respectively

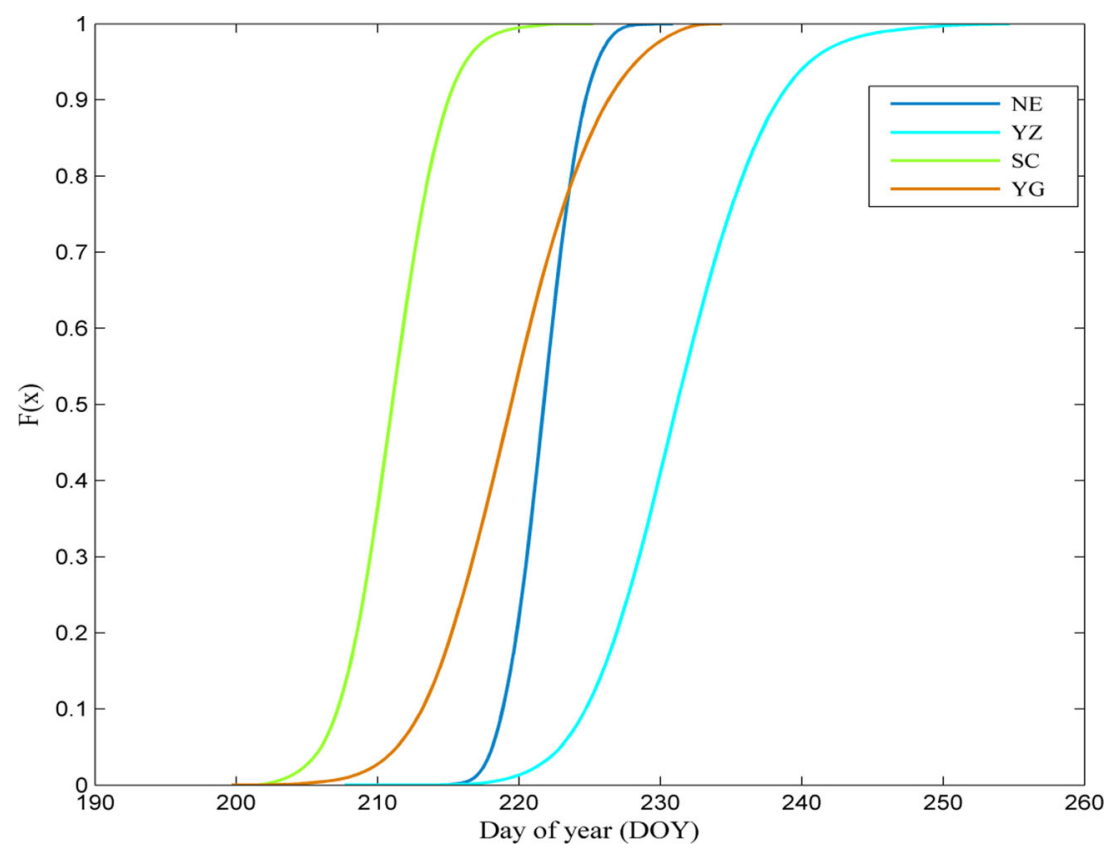

of the trends in the heading-flowering stages was also found at the GER scales.

The trends at three scales (AMS, GAS, and GER) across each cultivation region were compared to demonstrate the consistency of the FBM and the SBM in reflecting the phenology trends (Fig. 9). During 2000-2009, the median value (days/year) was delayed by 0.20 for the observed stages at the AMS scale and 0.39 and 0.12 for the estimated stages at the GAS and GER scales, respectively, in NE. However, in $\mathrm{YZ}$, the median value was advanced by $0.22,0.05$, and 0.11 at

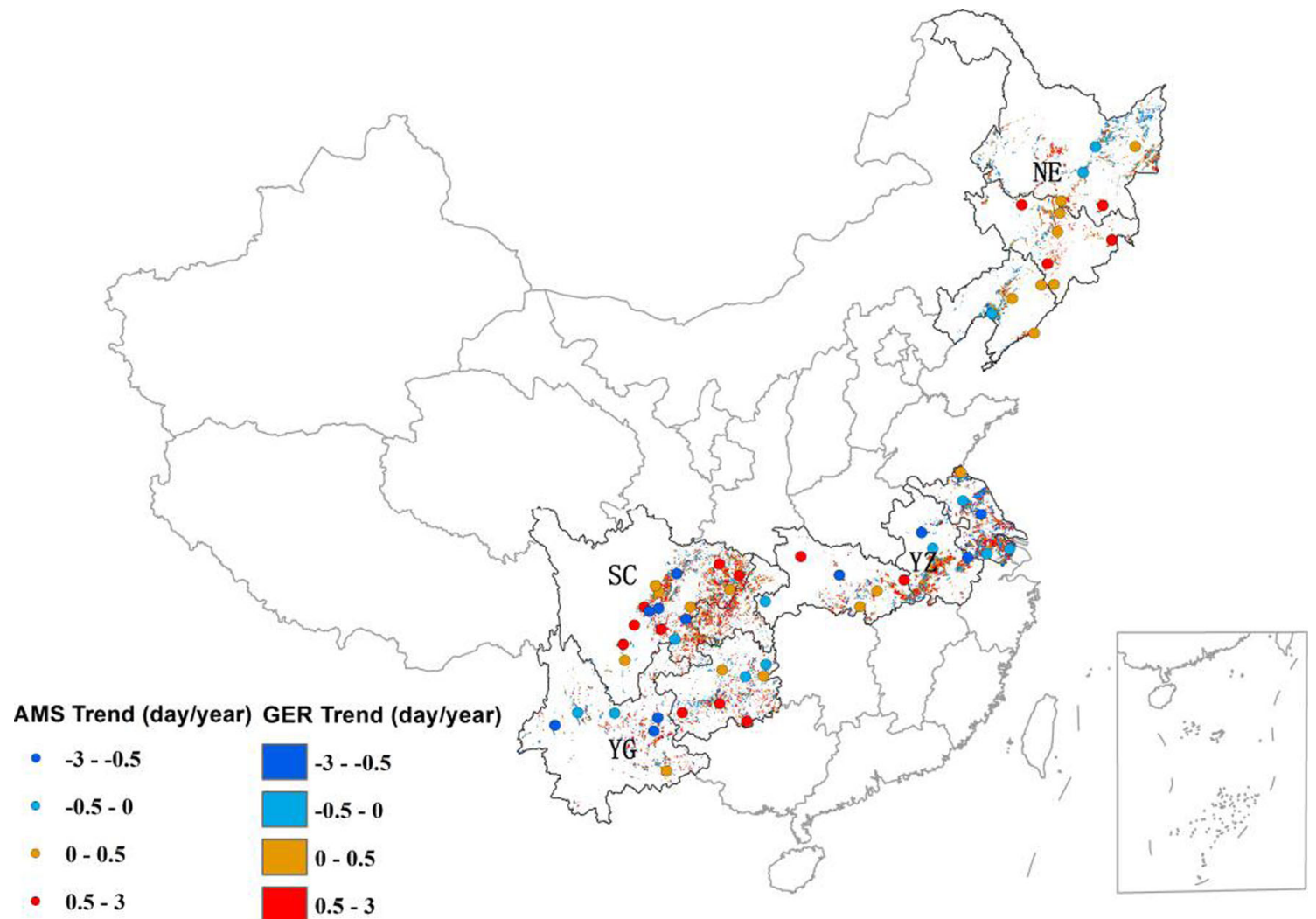

Fig. 8 The spatial distribution patterns of the temporal trends of annual heading-flowering stages of single rice (day/year) at AMS and GER scales in China during 2000-2009 
Fig. 9 Box plot of trends in heading-flowering stages of single rice across NE, YZ, SC, and $\mathrm{YG}$ at AMS, GAS, and GER scales respectively, during 2000 2009

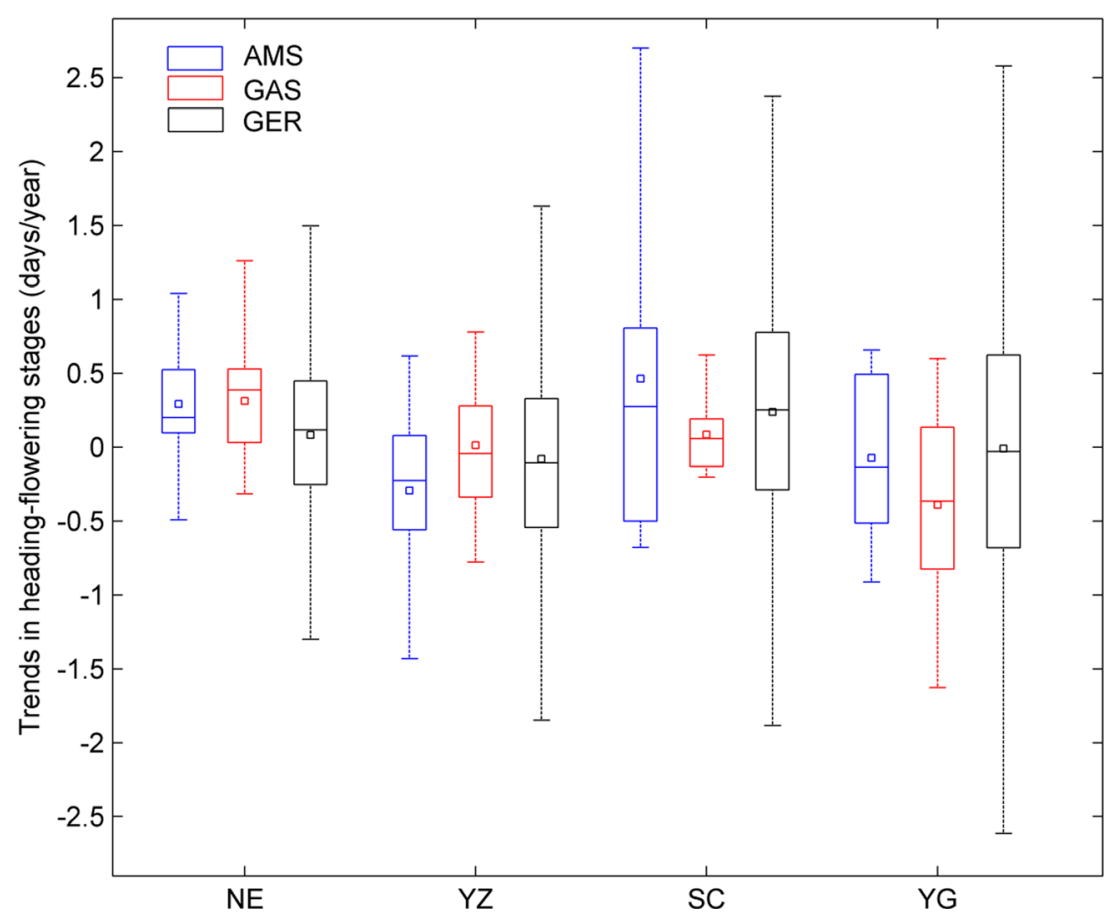

the AMS, GAS, and GER scales, respectively. Similarly, the median value was delayed by $0.27,0.06$, and 0.25 at the AMS, GAS, and GER scales, respectively, in SC and advanced by $0.14,0.36$, and 0.03 at the AMS, GAS, and GER scales, respectively, in YG. Besides, the regional average value (days/year) were $0.293,0.314$, and 0.083 in NE, -0.292 , 0.012 , and -0.081 in YZ, 0.464, 0.084, and 0.237 in SC and $-0.072,-0.388$, and -0.011 in YG at AMS, GAS, and GER scales, respectively.

\section{Discussion}

Comparisons of the spatiotemporal patterns of the headingflowering stages at three spatial scales

To test the differences of the spatiotemporal patterns of the heading-flowering stages at three spatial scales, one-way ANOVA was used to compare the regional average value and trends of the heading-flowering dates at three scales, and a non-parametric test was applied due to the heterogeneity of variance of samples at three scales. The results indicated that no significant differences $(p>0.05)$ were tested at three scales in all of the four regions, which demonstrated the consistency of both the FBM and the SBM. The SBM was demonstrated to be a more effective method to obtain phenological information than the FBM due to its wider coverage. However, in different regions, the ranges of data at three scales were found to be different. Generally, the data range at the GER scale was larger than that at the GAS scale due to the differences in the spatial coverage. At the AMS scale in $\mathrm{YZ}$ and $\mathrm{SC}$, the ranges of the key phenological stages were larger than those at the other two scales, while they were much closer in NE. Such results could be attributed to the different simulating ability of the SBM in each region, which had been observed in previous results. A gap exists between the SBM and the FBM, which could be due to the fact that $23.69 \%$ cases at the AMS and GAS scales exceeded \pm 10 days estimation error overall. For temporal trends, the average value of the trends also had no significant differences at three scales. However, the range of the temporal trends at the GER scale was much larger than those of the other two scales since large spatial coverage contributed much to the complex trends than at the station scales.

Potential reasons for the different spatial patterns of the key phenology stages between natural ecosystems and crop systems across China

Generally, the complexity of crop growth and phenology was largely confounded by climatic and agronomic factors (Estrella et al. 2007; Liu et al. 2010). The necessary conditions for crop growth, such as favorable temperature, precipitation, solar radiation, and photoperiod, functioned as determinant factors on the choice of the crop species and the appropriate farming season (Tao et al. 2012; Zhang and Tao 2013). Moreover, human management of crops, such as cultivar shifts and the alteration of planting dates to adapt to climate change or avoid cold damage, also had a significant influence on the phenology (Tao et al. 2013). 
Regarding natural vegetation, climatic condition, such as temperature determined by latitude and elevation, was the key controlling factor of the spatial pattern of phenology. Phenology, such as the green-up onset stages delayed from low toward high latitudes in the East of China and with the increase of elevation in the West mountainous area of China, correspondingly lead to a similar spatial pattern for the heading stages (Cong et al. 2012). Regarding the four single rice cultivation zones, the annual accumulated temperature $\left(>10^{\circ} \mathrm{C}\right)$ was $2,000-3,100,4,500-5,500,4,500-6,000$, and $3,500-5,500{ }^{\circ} \mathrm{C}$ in $\mathrm{NE}, \mathrm{YZ}, \mathrm{SC}$, and $\mathrm{YG}$, respectively, which exhibited a large variance (Mei et al. 1988). In NE, the annual thermal accumulation was the lowest due to its high latitude location, while regions in $\mathrm{YZ}$ and $\mathrm{SC}$ were much higher, followed by YG. Hence, the heading stages of natural vegetation in NE located at high latitude should be later than that in YZ, SC, and YG due to the lower thermal condition. While at a similar latitude, the heading stages of natural vegetation were later in $\mathrm{YG}$ than in $\mathrm{YZ}$ and $\mathrm{SC}$ due to its higher elevation.

However, specific to crop systems (e.g., single rice), the estimated heading-flowering stages exhibited a diverse pattern. In Fig. 5, the median value of the heading-flowering stages in NE was later than those in SC and YG, which agreed with the characteristics of natural vegetation. The median value was, however, earlier than that in YZ. Compared with the short growth period in the north cultivation region, the growth period in $\mathrm{YZ}$ exhibited a larger time range per year, with a value of $4,500-6,000{ }^{\circ} \mathrm{C}$ for annual accumulated temperature $\left(>10^{\circ} \mathrm{C}\right)$. Therefore, aiming at maximization of the land use to take full advantage of thermal and water conditions, the sowing dates of single rice as the second crop for rotation were relatively later in $\mathrm{YZ}$, contributing to the later heading-flowering stages. In contrast to the SC region, despite the similar yearly thermal condition, the headingflowering stages of single rice was 10-20 days earlier than in the YZ region to avoid the early temperature drop in autumn caused by the special climate characteristics of the basin topography. Hence, for crop systems, the dates of sowing and heading-flowering were dependent not only on temperature but also on the decision of farmers (Estrella et al. 2007). Much attention should be paid to the knowledge gaps with respect to the difference between the phenology of the crop systems and the natural vegetation influenced by human factors.

Potential reasons for the different responses of the key phenology stages to warming between crop systems and natural ecosystems across China

Trends in the key phenological stages based on the FBM and the SBM at the AMS, GAS, and GER scales in four regions are shown in Fig. 9. At the AMS scale, the median value of the heading dates was delayed by 0.20 and 0.27 days/year in NE and SC, respectively, and advanced by 0.22 and 0.14 days/ year in $\mathrm{YZ}$ and $\mathrm{YG}$, respectively. With respect to the trends at both the GAS and GER scales, they remained consistent with the trends at the AMS scale derived from FBM generally.

It is well known that temperature is the most important driver to crop phenology, which has been studied on a variety of agricultural crops using phenological data from filed trials, simulation models and satellite observations (Yao et al. 2007; Devries et al. 2011; Li et al. 2012; Lobell et al. 2012). For most natural vegetation, a warming climate significantly influenced the shifts of phenology. Advances in spring onset, delays in autumn senescence and consequently longer growing seasons were detected in temperate zones due to the continuing rise in temperature (Jeong et al. 2011; Vitasse et al. 2011; IPCC 2013). Lu et al. (2006) also found that flowering dates for four woody plants advanced from 0.05 to 0.175 days/year in the low plain and $0.125-0.375$ days/year on the plateau across China on the assumption of a $0.25{ }^{\circ} \mathrm{C}$ increase in the spring temperatures per decade.

By contrast, the trends of the heading-flowering stages for single rice detected in this study varied in different agroecological zones. Contrary to the natural vegetation, the diverse pattern of the phenological trends of single rice was ascribed to the combined effects of temperature change and cultivar shifts. Previous studies indicated that the length of growth period was negatively correlated with the mean temperature during the growth period of single rice in different agro-ecological zones (Liu et al. 2012; Zhang et al. 2013). Correspondingly, the rice growth period in China should be shortened over the past decades due to climate warming. However, the actual lengths of growth period for single rice were detected to increase significantly at most stations due to the adoption of late ripening cultivars for single rice to take advantage of the increased heat resources as an adaption measure for climate change (Tao et al. 2013; Zhang et al. 2014). Thus, the strength of the cultivar shifts on rice phenology relative to the temperature influences determined the diverse trends pattern in heading-flowering dates of single rice in different agro-ecological zones for the recent decade.

\section{Conclusions}

Compared with the FBM, the study demonstrated the rationality of detecting and monitoring phenological variations using the SBM at a national scale. The spatiotemporal variability of the heading-flowering stages was detected and compared at the AMS, GAS, and GER scales. At the AMS and GAS scales, one-to-one comparison between the observed and the estimated heading-flowering stages indicated that 52.62 and $76.31 \%$ of the cases were within \pm 5 and \pm 10 days estimation errors, respectively, for the entire single 
rice cultivation region, with a RMSE of 8.76 days. At the AMS and GER scales, the spatial pattern indicated that the annual average heading-flowering stages were much earlier in $\mathrm{SC}$ than in the other regions, followed by $\mathrm{YG}, \mathrm{NE}$, and $\mathrm{YZ}$, which was inconsistent with those of the natural ecosystems mainly depending on climatic condition determined by latitude and elevation. The probability distribution curves were also derived through kernel density estimation in the four regions. Moreover, delayed heading-flowering stages were detected in NE and SC while advanced stages were found in $\mathrm{YZ}$ and YG at three scales. Such diverse trends in crop systems could be attributed not only to the changing climate but also to agronomic factors, such as cultivar shifts. Furthermore, no significant differences $(p>0.05)$ of both the regional average value of the phenological stages and the trends were tested in all of the four regions, which demonstrated the consistency between the FBM and the SBM. The potential of the SBM to capture both the spatial and temporal variability of the heading-flowering stages of single rice at the national scale should be emphasized. Besides, dynamic land use data year by year to identify the typical rice-growing area and different smoothing methods to compare the applicability in different regions could also be included in the future study.

Acknowledgments This study was funded by the Fund for Creative Research Groups of National Natural Science Foundation of China (no. 41321001), the State Key Laboratory of Earth Surface Processes and Resource Ecology of Beijing Normal University (2014-ZY-06), the Programme of Introducing Talents of Discipline to Universities (B08008), and the Integrated Risk Governance Project (2013DFG20710) by the Ministry of Science and Technology of China.

\section{References}

Badeck F-W, Bondeau A, Böttcher K, Doktor D, Lucht W, Schaber J, Sitch S (2004) Responses of spring phenology to climate change. New Phytol 162(2):295-309. doi:10.1111/j.14698137.2004.01059.x

Bradley NL, Leopold AC, Ross J, Huffaker W (1999) Phenological changes reflect climate change in Wisconsin. Proc Natl Acad Sci U S A 96(17):9701-9704. doi:10.1073/pnas.96.17.9701

Bradley BA, Jacob RW, Hermance JF, Mustard JF (2007) A curve fitting procedure to derive inter-annual phenologies from time series of noisy satellite NDVI data. Remote Sens Environ 106(2):137-145. doi:10.1016/j.rse.2006.08.002

Chen J, Jönsson P, Tamura M, Gu Z, Matsushita B, Eklundh L (2004) A simple method for reconstructing a high-quality NDVI time-series data set based on the Savitzky-Golay filter. Remote Sens Environ 91(3-4):332-344. doi:10.1016/j.rse.2004.03.014

Chen X, Hu B, Yu R (2005) Spatial and temporal variation of phenological growing season and climate change impacts in temperate eastern China. Glob Chang Biol 11(7):1118-1130. doi:10.1111/j.13652486.2005.00974.x

Chmielewski F-M, Müller A, Bruns E (2004) Climate changes and trends in phenology of fruit trees and field crops in Germany, 1961-2000. Agric For Meteorol 121(1-2):69-78. doi:10.1016/S0168-1923(03) 00161-8
Cong N, Piao S, Chen A, Wang X, Lin X, Chen S, Han S, Zhou G, Zhang $X$ (2012) Spring vegetation green-up date in China inferred from SPOT NDVI data: a multiple model analysis. Agric For Meteorol 165:104-113. doi:10.1016/j.agrformet.2012.06.009

Devries ME, Leffelaar PA, Sakane N, Bado BV, Giller KE (2011) Adaptability of irrigated rice to temperature change in Sahelian environments. Exp Agric 47(1):69-87. doi:10.1017/ s0014479710001328

Dingkuhn M, Le Gal P-Y (1996) Effect of drainage date on yield and dry matter partitioning in irrigated rice. Field Crop Res 46(1-3):117126. doi:10.1016/0378-4290(95)00094-1

Doi H, Takahashi M, Katano I (2010) Genetic diversity increases regional variation in phenological dates in response to climate change. Glob Chang Biol 16(1):373-379. doi:10.1111/j.1365-2486.2009.01993.x

Estrella N, Sparks TH, Menzel A (2007) Trends and temperature response in the phenology of crops in Germany. Glob Chang Biol 13(8): 1737-1747. doi:10.1111/j.1365-2486.2007.01374.x

Fitter AH, Fitter RSR (2002) Rapid changes in flowering time in British plants. Science 296(5573):1689-1691. doi:10.1126/science. 1071617

Foerster S, Kaden K, Foerster M, Itzerott S (2012) Crop type mapping using spectral-temporal profiles and phenological information. Comput Electron Agric 89:30-40. doi:10.1016/j.compag.2012.07. 015

García-Mozo H, Mestre A, Galán C (2010) Phenological trends in southern Spain: a response to climate change. Agric For Meteorol 150(4): 575-580. doi:10.1016/j.agrformet.2010.01.023

Holben BN (1986) Characteristics of maximum-value composite images from temporal AVHRR data. Int J Remote Sens 7(11):1417-1434. doi:10.1080/01431168608948945

Howell D (2002) Statistical methods for psychology. Duxbury. p 324 325

Huang J, Wang X, Li X, Tian H, Pan Z (2013) Remotely sensed rice yield prediction using multi-temporal NDVI data derived from NOAA's-AVHRR. PLoS ONE 8(8). doi:10.1371/journal. pone.0070816

Ibanez I, Primack RB, Miller-Rushing AJ, Ellwood E, Higuchi H, Lee SD, Kobori H, Silander JA (2010) Forecasting phenology under global warming. Philos Trans R Soc B Biol Sci 365(1555):32473260. doi:10.1098/rstb.2010.0120

IPCC (2013) Summary for Policymakers. In: Stocker TF, Qin D, Plattner GK, Tignor M, Allen SK, Boschung J, Nauels A, Xia Y, Bex V, and Midgley PM (eds) Climate Change 2013: The Physical Science Basis. Contribution of Working Group I to the Fifth Assessment Report of the Intergovernmental Panel on Climate Change Cambridge University Press, Cambridge, United Kingdom and New York, USA

Jeganathan C, Dash J, Atkinson PM (2014) Remotely sensed trends in the phenology of northern high latitude terrestrial vegetation, controlling for land cover change and vegetation type. Remote Sens Environ 143:154-170. doi:10.1016/j.rse.2013.11.020

Jeong S-J, Ho C-H, Gim H-J, Brown ME (2011) Phenology shifts at start vs. end of growing season in temperate vegetation over the Northern Hemisphere for the period 1982-2008. Glob Chang Biol 17(7): 2385-2399. doi:10.1111/j.1365-2486.2011.02397.x

Jonsson P, Eklundh L (2002) Seasonality extraction by function fitting to time-series of satellite sensor data. IEEE Trans Geosci Remote Sens 40(8):1824-1832. doi:10.1109/TGRS.2002.802519

Jonsson P, Eklundh L (2004) TIMESAT — a program for analyzing timeseries of satellite sensor data. Comput Geosci 30(8):833-845. doi: 10.1016/j.cageo.2004.05.006

Karlsen S, Hogda K, Wielgolaski F, Tolvanen A, Tommervik H, Poikolainen J, Kubin E (2009) Growing-season trends in Fennoscandia 1982-2006, determined from satellite and phenology data. Clim Res 39(3):275-286. doi:10.3354/cr00828

Kross A, Fernandes R, Seaquist J, Beaubien E (2011) The effect of the temporal resolution of NDVI data on season onset dates and trends 
across Canadian broadleaf forests. Remote Sens Environ 115(6): 1564-1575. doi:10.1016/j.rse.2011.02.015

Li Z, Tang H, Yang P, Wu W, Chen Z, Zhou Q, Zhang L, Zou J (2012) Spatio-temporal responses of cropland phenophases to climate change in Northeast China. J Geogr Sci 22(1):29-45. doi:10.1007/ s11442-012-0909-2

Li Z, Yang P, Tang H, Wu W, Yin H, Liu Z, Zhang L (2014) Response of maize phenology to climate warming in Northeast China between 1990 and 2012. Reg Environ Chang 14(1):39-48. doi:10.1007/ s10113-013-0503-X

Liu Y, Wang E, Yang X, Wang J (2010) Contributions of climatic and crop varietal changes to crop production in the North China Plain, since 1980s. Glob Chang Biol 16(8):2287-2299. doi:10.1111/j. 1365-2486.2009.02077.x

Liu L, Wang E, Zhu Y, Tang L (2012) Contrasting effects of warming and autonomous breeding on single-rice productivity in China. Agric Ecosyst Environ 149:20-29. doi:10.1016/j.agee.2011.12.008

Lobell DB, Sibley A, Ivan Ortiz-Monasterio J (2012) Extreme heat effects on wheat senescence in India. Nat Clim Chang 2(3):186189. doi: $10.1038 /$ nclimate 1356

Lu P, Yu Q, Liu H, He Q (2006) Effects of changes in spring temperature on flowering dates of woody plants across China. Bot Stud 47(2): $153-161$

McCloy KR, Lucht W (2004) Comparative evaluation of seasonal patterns in long time series of satellite image data and simulations of a global vegetation model. IEEE Trans Geosci Remote Sens 42(1): 140-153. doi:10.1109/tgrs.2003.817811

Mei F, Wu X, Yao C et al (1988) Rice cropping regionalization in China. Chin J Rice Sci 2(3):97-110 (in Chinese with English abstract)

Menzel A, Estrella N, Fabian P (2001) Spatial and temporal variability of the phenological seasons in Germany from 1951 to 1996. Glob Chang Biol 7(6):657-666. doi:10.1111/j.1365-2486.2001.00430.x

Menzel A, Sparks TH, Estrella N, Koch E, Aasa A, Ahas R, Alm-KÜBler K, Bissolli P, BraslavskÁ OG, Briede A, Chmielewski FM, Crepinsek Z, Curnel Y, Dahl Å, Defila C, Donnelly A, Filella Y, Jatczak K, MÅGe F, Mestre A, Nordli Ø, PeÑUelas J, Pirinen P, RemiŠOvÁ V, Scheifinger H, Striz M, Susnik A, Van Vliet AJH, Wielgolaski F-E, Zach S, Zust ANA (2006) European phenological response to climate change matches the warming pattern. Global Change Biology 12(10):1969-1976. doi:10.1111/j.1365-2486. 2006.01193.x

Moldenhauer K, Slaton N (2001) Rice growth and development. In: Slaton NA (ed) Rice production handbook. Misc. Publ. 192. Coop. Ext. Serv., Univ. of Arkansas, Little Rock, pp 7-14

Morin X, Roy J, Sonié L, Chuine I (2010) Changes in leaf phenology of three European oak species in response to experimental climate change. New Phytol 186(4):900-910. doi:10.1111/j.1469-8137. 2010.03252.x

Papademetrieu MK (ed.) (2000) Bridging the rice yield gap in the AsiaPacific Region. FAO RAP Publication, p 219

Piao S, Fang J, Zhou L, Ciais P, Zhu B (2006) Variations in satellitederived phenology in China's temperate vegetation. Glob Chang Biol 12(4):672-685. doi:10.1111/j.1365-2486.2006.01123.x

Romanovskaja D, Kalvane G, Briede A, Baksiene E (2009) The influence of climate warming on the changes of the length of phenological seasons in Lithuania and Latvia. Zemdirbyste-Agriculture 96(4): 218-231

Sacks WJ, Kucharik CJ (2011) Crop management and phenology trends in the U.S. Corn Belt: Impacts on yields, evapotranspiration and energy balance. Agric For Meteorol 151(7):882-894. doi:10.1016/j. agrformet.2011.02.010

Sakamoto T, Wardlow BD, Gitelson AA, Verma SB, Suyker AE, Arkebauer TJ (2010) A Two-Step Filtering approach for detecting maize and soybean phenology with time-series MODIS data. Remote Sens Environ 114(10):2146-2159. doi:10.1016/j.rse.2010. 04.019
Savitzky A, Golay MJE (1964) Smoothing and differentiation of data by simplified least squares procedures. Anal Chem 36(8):1627-1639. doi:10.1021/ac60214a047

Sehgal VK, Jain S, Aggarwal PK, Jha S (2011) Deriving crop phenology metrics and their trends using times series NOAA-AVHRR NDVI Data. J Indian Soc Remote Sens 39(3):373-381. doi:10.1007/ s12524-011-0125-Z

Setiyono TD, Weiss A, Specht J, Bastidas AM, Cassman KG, Dobermann A (2007) Understanding and modeling the effect of temperature and daylength on soybean phenology under high-yield conditions. Field Crop Res 100(2-3):257-271. doi:10.1016/j.fcr. 2006.07 .011

Sheather SJ (2004) Density estimation. Stat Sci 19(4):588-597. doi:10 1214/088342304000000297

Siebert S, Ewert F (2012) Spatio-temporal patterns of phenological development in Germany in relation to temperature and day length. Agric For Meteorol 152:44-57. doi:10.1016/j.agrformet.2011.08. 007

Sparks TH, Carey PD (1995) The Responses of Species to Climate Over Two Centuries: An Analysis of the Marsham Phenological Record, 1736-1947. J Ecol 83(2):321-329. doi:10.2307/2261570

Sparks TH, Jeffree EP, Jeffree CE (2000) An examination of the relationship between flowering times and temperature at the national scale using long-term phenological records from the UK. Int $\mathbf{J}$ Biometeorol 44(2):82-87. doi:10.1007/s004840000049

Sun W, Huang Y (2011) Global warming over the period 1961-2008 did not increase high-temperature stress but did reduce low-temperature stress in irrigated rice across China. Agric For Meteorol 151(9): 1193-1201. doi:10.1016/j.agrformet.2011.04.009

Sun H, Huang J, Peng D (2009) Detecting major growth stages of paddy rice using MODIS data. J Remote Sens 13(6):1122-1137

Tao F, Zhang S, Zhang Z (2012) Spatiotemporal changes of wheat phenology in China under the effects of temperature, day length and cultivar thermal characteristics. Eur J Agron 43:201-212. doi: 10.1016/j.eja.2012.07.005

Tao F, Zhang Z, Shi W, Liu Y, Xiao D, Zhang S, Zhu Z, Wang M, Liu F (2013) Single rice growth period was prolonged by cultivars shifts, but yield was damaged by climate change during 1981-2009 in China, and late rice was just opposite. Glob Chang Biol 19(10): 3200-3209. doi:10.1111/gcb.12250

Thornton PK, Jones PG, Alagarswamy G, Andresen J (2009) Spatial variation of crop yield response to climate change in East Africa. Glob Environ Chang 19(1):54-65. doi:10.1016/j.gloenvcha.2008. 08.005

Tubiello FN, Soussana J-F, Howden SM (2007) Crop and pasture response to climate change. Proc Natl Acad Sci U S A 104(50): 19686-19690. doi:10.1073/pnas.0701728104

Vitasse Y, François C, Delpierre N, Dufrêne E, Kremer A, Chuine I, Delzon S (2011) Assessing the effects of climate change on the phenology of European temperate trees. Agric For Meteorol 151(7): 969-980. doi:10.1016/j.agrformet.2011.03.003

Wang X, Piao S, Ciais P, Li J, Friedlingstein P, Koven C, Chen A (2011) Spring temperature change and its implication in the change of vegetation growth in North America from 1982 to 2006. Proc Natl Acad Sci U S A 108(4):1240-1245. doi:10. 1073/pnas. 1014425108

Wang H, Chen J, Wu Z, Lin H (2012) Rice heading date retrieval based on multi-temporal MODIS data and polynomial fitting. Int J Remote Sens 33(6):1905-1916. doi:10.1080/01431161.2011.603378

Wu W, Yang P, Tang H, Zhou Q, Chen Z, Shibasaki R (2010) Characterizing spatial patterns of phenology in cropland of China based on remotely sensed data. Agric Sci China 9(1):101-112. doi: 10.1016/s1671-2927(09)60073-0

Yao F, Xu Y, Lin E, Yokozawa M, Zhang J (2007) Assessing the impacts of climate change on rice yields in the main rice areas of China. Clim Chang 80(3-4):395-409. doi:10.1007/s10584-006-9122-6 
Zhang S, Tao F (2013) Modeling the response of rice phenology to climate change and variability in different climatic zones: comparisons of five models. Eur J Agron 45:165-176. doi:10.1016/j.eja. 2012.10.005

Zhang T, Huang Y, Yang X (2013) Climate warming over the past three decades has shortened rice growth duration in China and cultivar shifts have further accelerated the process for late rice. Glob Chang Biol 19(2):563-570. doi:10.1111/gcb.12057

Zhang S, Tao F, Zhang Z (2014) Rice reproductive growth duration increased despite of negative impacts of climate warming across China during 1981-2009. Eur J Agron 54:70-83. doi:10.1016/j.eja. 2013.12.001 